\title{
Glucose-6-Phosphate Dehydrogenase Activity
}

National Cancer Institute

\section{Source}

National Cancer Institute. Glucose-6-Phosphate Dehydrogenase Activity. NCI Thesaurus.

Code C139065.

The determination of the amount of glucose-6-phosphate dehydrogenase activity present in a sample. 